\title{
The role of corneal hysteresis during the evaluation of patients with possible normal-tension glaucoma
}

This article was published in the following Dove Press journal: Clinical Ophthalmology

\author{
Ming Chen' \\ Laura Kueny ${ }^{2}$ \\ Arthur L Schwartz ${ }^{2}$ \\ 'Department of Surgery, Division of \\ Ophthalmology, University of Hawaii, \\ Honolulu, HI, USA; ${ }^{2}$ Department \\ of Ophthalmology, Georgetown \\ University, Washington, DC, USA
}

Purpose: There are multiple reports of the role of corneal hysteresis $(\mathrm{CH})$ as an independent risk factor for the diagnosis and risk of progression of normal-tension glaucoma (NTG). Our study measured $\mathrm{CH}$ with the Ocular Response Analyzer (ORA) in patients with intraocular pressure (IOP) $<21 \mathrm{mmHg}$ to investigate if a low $\mathrm{CH}$ would identify NTG in this Asianbased practice.

Methods: This was a prospective cross-sectional study of patients who underwent routine eye examination during 2016 in a private practice in Honolulu, Hawaii, where most patients are Asian. Inclusion criteria are: 1) $\geq 65$ years 2) IOP $<21$ (compensated IOP by ORA), and 3) $\mathrm{CH}$ values $<10$ using ORA as measured by a single experienced technician. Exclusion criteria are: 1) sight-limiting ocular or corneal disease that would preclude accurate measurements for the purposes of the study. 2) Any patient who had difficulty in being tested with the ORA. 3) Patients who had any history of any type of glaucoma. All patients that met the inclusion criteria underwent fundus photography to measure cup-to-disc ratio and cup-to-disc asymmetry and also had central corneal thickness measured. Thickness of the retina nerve fiber layer was measured by ocular coherence tomography. The eyes with an average retina nerve fiber layer thickness less than $80 \mu \mathrm{m}$ were classified as possible NTG and were scheduled for a visual field test. The field examination was considered valid only if the fixation, false positives, and false negatives were within the acceptable range. Patient demographics and data on preexisting diseases were collected including age, sex, coexisting medical conditions, and previous intraocular surgery. Those with thinning of retina nerve fiber layer on optical coherence tomography had a Humphrey visual field test to confirm the diagnosis of glaucoma.

Results: Seventy-six eyes of 46 patients that met the eligibility criteria were included in the study. Twenty-one previously undiagnosed eyes were confirmed as having NTG, which corresponds to an incidence of $27.6 \%$.

Conclusion: $\mathrm{CH}$ measurement is a valuable test to assist in early diagnosis of NTG, especially in the elderly Asian population. With an established diagnosis, aggressive early treatments medically or surgically to further lower IOP can prevent irreversible blindness, which can severely impact the patient's family and socioeconomic status.

Keywords: glaucoma, normal-tension glaucoma, intraocular pressure, corneal hysteresis, Ocular Response Analyzer

\section{Introduction}

Glaucoma is a silent and sight-threatening disease caused by slowly progressive damage to the optic nerve. In patients over the age of 60 , glaucoma is the leading cause of blindness. ${ }^{1}$ The estimated prevalence of glaucoma in the USA is 3 million, and up to one half of these cases are undiagnosed. ${ }^{1}$ Glaucoma affects more than 70 million people worldwide, $10 \%$ of whom are bilaterally blind, and $50 \%-90 \%$ are undiagnosed. ${ }^{2,3}$ 
This prevalence is expected to increase in parallel with the increasing life expectancies to 111.8 million in the year $2040 .^{3}$ Despite its significance, the underlying pathogenesis of glaucoma remains largely mysterious. Moreover, its diagnosis is often delayed as a majority of patients remain asymptomatic until the late stages and since awareness among the general population is relatively low. . $^{-7}$

Early detection of glaucoma is the key for prevention of progressive visual loss with the treatment of aggressively lowering intraocular pressure (IOP). Normal-tension glaucoma (NTG) is particularly hard to detect given that the IOP is within normal limits, especially in the Japanese population. It is often overlooked until a late stage, which leads to irreversible visual impairment. In a recent review of population-based glaucoma prevalence, the calculated mean proportion of NTG was larger in Asian (76.3\%) than in a white population $(33.7 \%){ }^{8}$

To date, the highest NTG proportion reported was $92.0 \%$, from the Tajimi Study ${ }^{6}$ conducted in Japan, and the lowest was 30\%, from the Italian Egna-Neumarkt Study. ${ }^{9}$

Use of a fundus ophthalmoscope together with fundus camera photography is a good way to detect abnormalities in the disc such as irregularity, paleness, large cup size, hemorrhage, or loss of rim to diagnose low-tension glaucoma. However, hazy media from coexisting cataract or other eye pathologies prohibit a good examination, in addition to possible poor cooperation for detailed examination by patients.

One of the reasons that IOP is always lower than true pressure is the weakness of cornea biomechanics from aging or various corneal diseases and gives the reading of normal intraocular pressure from various tonometry, hence delay the treatment for years until irreversible vision loss occur and then bring patients to see eye professionals.

Corneal biomechanical properties are correlated and associated with the progression of visual field damage in NTG patients as indicated in many previous studies (Table 1). Corneal hysteresis $(\mathrm{CH})$ is a mechanical property of the cornea that can affect the accuracy of IOP measurement. Several recent studies suggest that low $\mathrm{CH}$ is a risk factor for the development of glaucoma. ${ }^{10}$ These findings also suggest that $\mathrm{CH}$ (Figure 1) can be used as one of the diagnostic and prognostic factors for progression of NTG that is independent of corneal thickness or IOP.

We thus studied a series of cases to detect NTG by using Ocular Response Analyzer (ORA, Reichert instruments, Depew, NY, USA) to check CH (Figure 1) as one of the screening methods and to confirm the diagnosis with optical coherence tomography (OCT) and visual field test. $\mathrm{CH}$ below $10 \mathrm{mmHg}$ was considered low for this study.

\section{Methods}

The study was conducted in this single general ophthalmologic practice where the ORA was available. Those patients without any history of glaucoma aged 65 years and older with IOP consistently below $21 \mathrm{mmHg}$ and $\mathrm{CH}$ below $10 \mathrm{mmHg}$ were included in the study (Table 2). Patients with severe corneal disease eye such as opacity and/or keratitis were excluded due to possible ORA reading errors. In order for reliable visual field and OCT exam, the patients included were educated to understand the visual field test.

Table I Chronological list of studies correlating $\mathrm{CH}$ and glaucoma

\begin{tabular}{|c|c|}
\hline Study & Findings \\
\hline Congdon et al,"' 2006 & Low $\mathrm{CH}$, not $\mathrm{CCT}$, is associated with progression of visual field loss over 5 years \\
\hline Bochmann et al, ${ }^{12} 2008$ & $\mathrm{CH}$ is lower in patients with acquired pits of the optic nerve independent of IOP \\
\hline Sullivan-Mee et al, ${ }^{13} 2008$ & $\begin{array}{l}\mathrm{CH} \text { is lower in patients with glaucoma than patients with OHTN, GS, or normal eyes independent of other } \\
\text { risk factors }\end{array}$ \\
\hline Wells et al, ${ }^{14} 2008$ & Low $\mathrm{CH}$ is associated with increased mean cup depth independent of CCT and IOP \\
\hline Abitbol et al, ${ }^{15} 2010$ & $\mathrm{CH}$ is lower in glaucomatous eyes than normal eyes, not independent from CCT \\
\hline Anand et al, ${ }^{16} 2010$ & $\begin{array}{l}\text { In asymmetric POAG, } \mathrm{CH} \text { is significantly lower in the eye with more glaucomatous damage as defined by VF } \\
\text { independent of IOP and CCT }\end{array}$ \\
\hline Hirneiss et al, ${ }^{17} 20 \mathrm{II}$ & In asymmetric POAG, there is no statistically significant difference between $\mathrm{CH}$ between the two eyes \\
\hline Narayanaswamy et al, ${ }^{18} 201 \mathrm{I}$ & $\mathrm{CH}$ is significantly lower in patients with PACG compared to normal eyes \\
\hline Grise-Dulac et al, ${ }^{19} 201 \mathrm{I}$ & $\mathrm{CH}$ is significantly lower in patients with NTG than in patients with POAG or normal eyes \\
\hline Morita et $a l,{ }^{20} 20 \mathrm{Il}$ & $\mathrm{CH}$ is significantly lower in patients with NTG, and CCT did not show a statistically significant difference \\
\hline Mansouri et al, ${ }^{21} 2012$ & Low $\mathrm{CH}$ was not associated with glaucomatous damage on multivariate analysis \\
\hline De Moraes et al, 222012 & Multivariate analysis demonstrating that $\mathrm{CH}$ has a stronger correlation with glaucomatous progression than $\mathrm{CCT}$ \\
\hline Kaushik et al, ${ }^{23} 2012$ & $\begin{array}{l}\mathrm{CH} \text { is significantly lower in patients with POAG and NTG in comparison to normal subjects independent of IOP } \\
\text { and CCT on multivariate analysis }\end{array}$ \\
\hline Prata et al, ${ }^{24} 2012$ & Low $\mathrm{CH}$ is associated with increased cup-to-disc ratio and mean cup depth, independent of IOP and disc size \\
\hline Vu et al, ${ }^{25} 2013$ & $\mathrm{CH}$ best correlates with mean deviation on VF in comparison to other structural markers of glaucomatous damage \\
\hline
\end{tabular}

Abbreviations: $\mathrm{CH}$, corneal hysteresis; CCT, central corneal thickness; GS, glaucoma suspect; IOP, intraocular pressure; NTG, normal-tension glaucoma; OHTN, ocular hypertension; PACG, primary angle closure glaucoma; POAG, primary-open angle glaucoma; $V F$, visual field. 


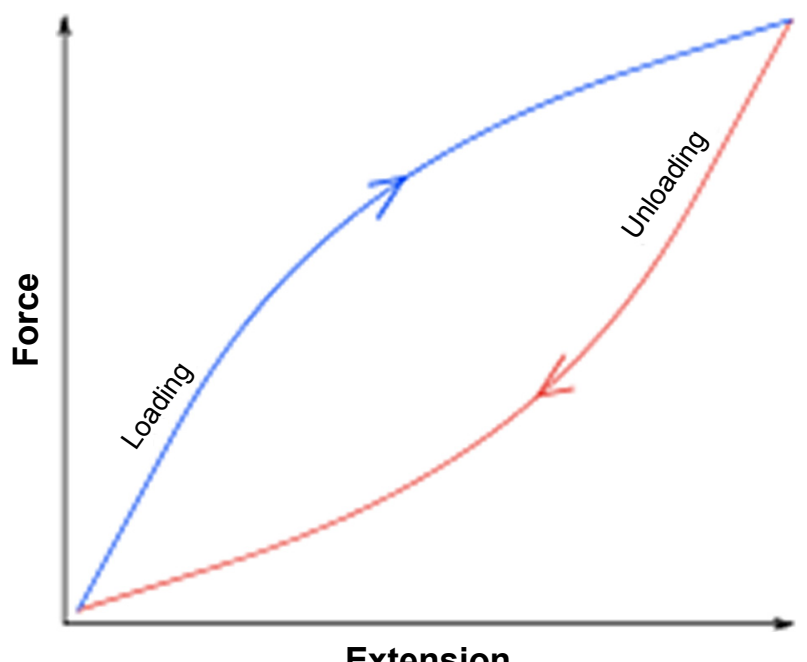

Extension

Figure I What is hysteresis and $\mathrm{CH}$ ?

Notes: Hysteresis is the difference in the behavior of the material between loading and unloading (eg, rubber band). $\mathrm{CH}$ is the difference between the pressure at which the cornea bends inward and the pressure at which the cornea bends outward. Abbreviation: $\mathrm{CH}$, corneal hysteresis.

Seventy-six eyes of 46 patients that met the eligibility criteria were included in the study. Comprehensive complete eye exams were performed that included $\mathrm{CH}$ measurement through ORA. Patients were selected according to the

Table 2 Characteristics of study subjects

\begin{tabular}{|c|c|c|c|}
\hline $\begin{array}{l}\text { Characteristics } \\
\mathrm{N}=\# \text { of eyes }\end{array}$ & $\begin{array}{l}\text { NTG, } \\
\mathbf{N}=21\end{array}$ & $\begin{array}{l}\text { Non-glaucoma } \\
\text { eyes, } \mathrm{N}=55\end{array}$ & $P$-value \\
\hline $\begin{array}{l}\text { Age, years, } \\
\text { mean } \pm \text { SD }\end{array}$ & $75.6 \pm 6.9$ & $78.5 \pm 7.9$ & 0.1473 \\
\hline $\begin{array}{l}\text { Gender } \\
\text { Female } \\
\text { Male }\end{array}$ & $\begin{array}{l}\text { I } 4(66.7) \\
7(33.3)\end{array}$ & $\begin{array}{l}27(49.1) \\
28(50.9)\end{array}$ & 0.1692 \\
\hline IOPc, mmHg & $15.1 \pm 2.9$ & $14.4 \pm 2.8$ & 0.3063 \\
\hline $\mathrm{CH}, \mathrm{mmHg}$ & $9.1 \pm 0.4$ & $8.9 \pm 0.7$ & 0.1922 \\
\hline IOPg, mmHg & $12.9 \pm 3.3$ & $11.8 \pm 3.2$ & 0.1820 \\
\hline $\mathrm{CCT}, \mathrm{mm}$ & $5 \mid 3.0 \pm 21.1$ & $513.5 \pm 21.9$ & 0.8129 \\
\hline $\mathrm{c} / \mathrm{d}$ & $0.6 \pm 0.2$ & $0.5 \pm 0.2$ & 0.0253 \\
\hline OCT & $75.3 \pm 7.6$ & $94.8 \pm 6.8$ & $<0.0001$ \\
\hline \multicolumn{4}{|l|}{ Laterality } \\
\hline Right & II (52.4) & $29(52.7)$ & 0.9784 \\
\hline Left & $10(47.6)$ & $26(47.3)$ & \\
\hline BCVA & & & 0.2046 \\
\hline $20 / 25$ & 7 (33.3) & II (20.0) & \\
\hline $20 / 30$ & $8(38.1)$ & $16(29.1)$ & \\
\hline $20 / 40$ & $3(14.3)$ & $22(40.0)$ & \\
\hline $20 / 50$ & $2(9.5)$ & $3(5.5)$ & \\
\hline $20 / 60$ & I (4.8) & $3(5.5)$ & \\
\hline Pseudophakia & $21(100)$ & $47(85.5)$ & 0.0975 \\
\hline DM & $3(14.3)$ & II (20.0) & 0.7453 \\
\hline Other CV RF & $17(81.0)$ & $37(67.3)$ & 0.2744 \\
\hline Asymmetry & $0(0.0)$ & $3(5.5)$ & 0.5564 \\
\hline
\end{tabular}

Note: Asymmetry indicates cup/disc (c/d) asymmetry between two eyes.

Abbreviations: BCVA, best-corrected visual acuity; $\mathrm{CH}$, corneal hysteresis; $\mathrm{CCT}$, central cornea thickness; c/d, cup/disc ratio; CV RF, cardiovascular risk factor; DM, diabetes mellitus; IOP, intraocular pressure; IOPc, compensated IOP reading with ORA; IOPg, Goldmann equivalent IOP read by ORA; NTG, normal-tension glaucoma; OCT, optical coherence tomography; ORA, ocular response analyzer. following criteria. Those with $\mathrm{CH}$ lower than $10 \mathrm{mmHg}$ were scheduled for OCT to check retina nerve fiber layer (RNFL) thickness. Those eyes that had a value lower than 80 on RNFL exam and significant loss of nerve fiber on the OCT were then assessed with a visual field examination. Visual field exam results were carefully evaluated by the patients medical doctor (MD) specializing in Ophthalmology, for any valid abnormality.

This study has been approved by the institutional review committee of the University of Hawaii, \# 2017-00386. All patients signed the inform consent to enter the study.

\section{Results}

Seventy-six eyes of 46 patients that met the eligibility criteria were included in the study. Twenty-one previously undiagnosed eyes were confirmed as having NTG, which corresponds to an incidence of $27.6 \%$ (Figure 2). We found no statistically significant difference between normal eyes and NTG eyes in $\mathrm{CH}(P=0.19)$; however, the average RNFL between normal eyes and NTG eyes had a statistically significant difference $(P<0.001)$ (Table 3$)$.

\section{Discussion}

As the lifespan of humans is increasing, the eyes of the elderly are also degenerating accordingly. The degeneration

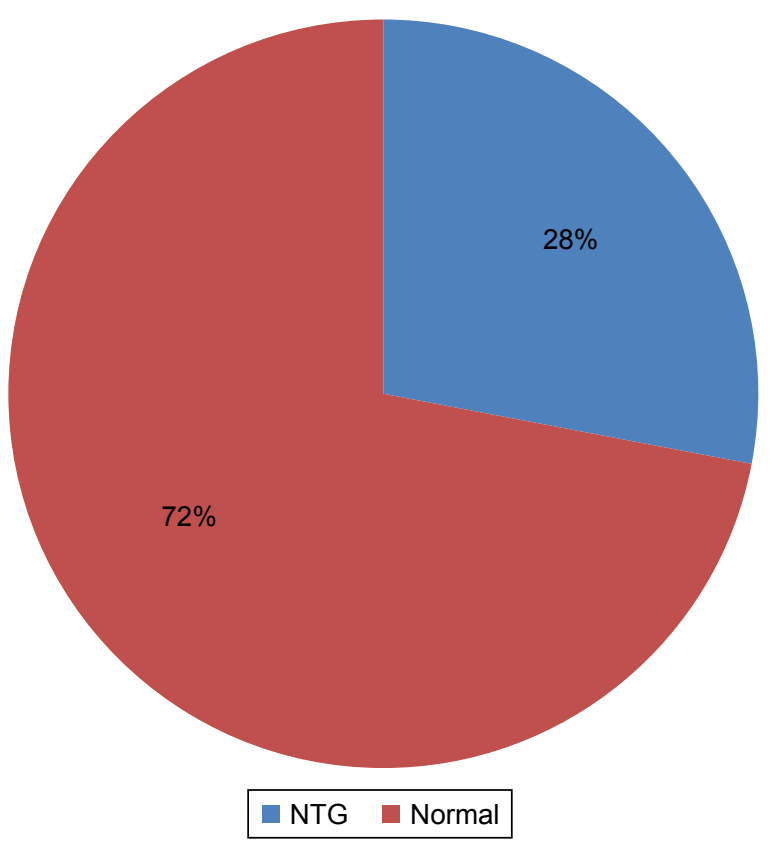

Figure 2 The percentage of NTG after screening those with the low $\mathrm{CH}$ (below 10) by OCT and visual field.

Abbreviations: NTG, normal-tension glaucoma; OCT, optical coherence tomography. 
Table 3 Comparison between two groups with respect to $\mathrm{CH}$ and average thickness of RNFL

\begin{tabular}{llll}
\hline Characteristic & $\begin{array}{l}\text { NTG, } \\
\mathbf{n}=\mathbf{2 1}\end{array}$ & $\begin{array}{l}\text { Non- } \\
\text { glaucoma } \\
\text { eyes, } \mathbf{n}=\mathbf{5 5}\end{array}$ & P-value \\
\hline $\mathrm{CH}, \mathrm{mmHg}$ & $9.1 \pm 0.4$ & $8.9 \pm 0.7$ & 0.19 \\
$\begin{array}{l}\text { OCT (average thickness } \\
\text { of RNFL, mm) }\end{array}$ & $75.3 \pm 7.6$ & $94.8 \pm 6.8$ & $<0.00 \mathrm{I}$ \\
\hline
\end{tabular}

Abbreviations: $\mathrm{CH}$, corneal hysteresis; NTG, normal-tension glaucoma; OCT, optical coherence tomography; RNFL, retina nerve fiber layer.

of cornea, optic nerve, and retina can affect visual ability and lifestyle of the elderly. Some of these patients were diagnosed as having NTG because they had vision loss with normal IOP. According to our study, patients who were Asian, older (above 75 years old), women, and having undergone cataract surgery made them more likely to have NTG.

Corneal degeneration causing low $\mathrm{CH}$ can give a normal reading for the measurement of IOP and delay the diagnosis of glaucoma. The IOP has a diurnal fluctuation varying throughout the 24 hours. Therefore some spiking of the IOP may never be detected. According to previous studies, the lowest IOP is usually seen after $2 \mathrm{pm}$, when some patients visit doctor for their IOP check. The highest is seen at $6 \mathrm{am}$ or in the night, due to the supine position when most of the patients are still in bed. ${ }^{26}$ Thus, a single office measurement of IOP does not adequately depict the degree of fluctuation in IOP. Some spiking of the IOP is never detected in this case. Even a minor increase in IOP in these elderly patients can cause serious optic nerve damage, especially if it has been going on for a period of time.

We still cannot treat aging and tissue degeneration, but we can aggressively treat these patients to lower IOP to prevent NTG and further loss of sight. Due to the visual field loss from NTG, safety for driving and even walking can be a big issue for these patients. The family or caregivers should be informed of the disability, which most patients may try to deny.

This study was conducted at a single office with a single calibrated ORA for accuracy. A single technician, who has done the test in over 20,000 cases in the past 2 years, performed the test in this study. Maintaining a correct posture and position in front of the machine were strict requirements for a reliable test result. The IOP readings were often compared with Goldmann applanation tonometry for consistency and agreement.

The majority of the participants (90\%) of this study were Asian. A possible reason for this high incidence in this practice of seeing patients with undiagnosed NTG could be due to the high Asian population and less attention being paid to this disease. It was rare to see Polynesians in this study population, and most of the patients were pure Chinese, Japanese, Korean, and Philippine immigrants. It may be due to education, economic, or cultural reasons that this population tends to be poorly educated and ignores NTG until an irreversible late stage is reached.

The results of this study confirm multiple other studies that showed that as many as $30 \%-50 \%$ of individuals in the general population who have glaucomatous optic neuropathy and visual field loss have initial screening IOPs below $22 \mathrm{mmHg}$. As glaucomatous optic neuropathy examination and visual field test can be challenging for elderly patients with NTG, CH can be an add-on diagnostic tool for NTG.

This study suggests considering measuring $\mathrm{CH}$ as a screening tool for NTG, especially in patients with risk factors.

\section{Conclusion}

$\mathrm{CH}$ measurement is a valuable test to assist in early diagnosis of NTG, especially in an elderly Asian population. Once the diagnosis of NTG is made, aggressive medical or surgical treatments to further lower IOP can prevent irreversible blindness, which can severely impact on the patients and their family.

\section{Disclosure}

The authors report no conflicts of interest in this work.

\section{References}

1. Boyd K. What is glaucoma? Am Acad Ophthalmol. Epub April 28, 2016.

2. Quigley HA, Broman AT. The number of people with glaucoma worldwide in 2010 and 2020. Br J Ophthalmol. 2006;90:262-267.

3. Weinreb RN, Aung T, Medeiros FA. The pathophysiology and treatment of glaucoma: a review. JAMA. 2014;311:1901-1911.

4. Topouzis F, Coleman AL, Harris A, et al. Factors associated with undiagnosed open-angle glaucoma: the Thessaloniki Eye Study. Am J Ophthalmol. 2008;145:327-335.

5. Chua J, Baskaran M, Ong PG, et al. Prevalence, risk factors, and visual features of undiagnosed glaucoma: the Singapore Epidemiology of Eye Diseases Study. JAMA Ophthalmol. 2015;133:938-946.

6. Iwase A, Suzuki Y, Araie M, et al. The prevalence of primary open-angle glaucoma in Japanese: the Tajimi Study. Ophthalmology. 2004;111: 1641-1648.

7. Ramakrishnan R, Nirmalan PK, Krishnadas R, et al. Glaucoma in a rural population of southern India: the Aravind comprehensive eye survey. Ophthalmology. 2003;110(8):1484-1490.

8. Cho HK, Kee C. Population-based glaucoma prevalence studies in Asians. Surv Ophthalmol. 2014;59:434-447.

9. Bonomi L, Marchini G, Marraffa M, et al. Prevalence of glaucoma and Intraocular pressure distribution in a defined population. The EgnaNeumarkt Study. Ophthalmology. 1998;105:209-215.

10. Medeiros F, Meira-Freitas D, Lisboa R, et al. Corneal hysteresis as a risk factor for glaucoma progression: a prospective longitudinal study. Ophthalmology. 2013;120(8):1533-1540. 
11. Congdon NG, Broman AT, Bandeen-Roche K, et al. Central corneal thickness and corneal hysteresis associated with glaucoma damage. Am J Ophthalmol. 2006;141:868-875.

12. Bochmann F, Ang GS, Azuara-Blanco A. Lower corneal hysteresis in glaucoma patients with acquired pit of the optic nerve (APON). Graefes Arch Clin Exp Ophthalmol. 2008;246:735-738.

13. Sullivan-Mee M, Billingsley SC, Patel AD, et al. Ocular response analyzer in subjects with and without glaucoma. Optom Vis Sci. 2008;85: 463-470.

14. Wells AP, Garway-Heath DF, Poostchi A, et al. Corneal hysteresis but not corneal thickness correlates with optic nerve surface compliance in glaucoma patients. Invest Ophthalmol Vis Sci. 2008;49:3262-3268.

15. Abitbol O, Bouden J, Doan S, et al. Corneal hysteresis measured with the ocular response analyzer in normal and glaucomatous eyes. Acta Ophthalmol. 2010;88:116-119.

16. Anand A, De Moraes CG, Teng CC, et al. Corneal hysteresis and visual field asymmetry in open angle glaucoma. Invest Ophthalmol Vis Sci. 2010;51:6514-6518.

17. Hirneiss C, Neubauer AS, Yu A, et al. Corneal biomechanics measured with the ocular response analyser in patients with unilateral open-angle glaucoma. Acta Ophthalmol. 2011;89:e189-e192.

18. Narayanaswamy A, Su DH, Baskaran M, et al. Comparison of ocular response analyzer parameters in Chinese subjects with primary angleclosure and primary open-angle glaucoma. Arch Ophthalmol. 2011;129: 429-434.

19. Grise-Dulac A, Saad A, Abitbol O, et al. Assessment of corneal biomechanical properties in normal tension glaucoma and comparison with open-angle glaucoma, ocular hypertension, and normal eyes. J Glaucoma. 2011;21:486-489.
20. Morita T, Shoji N, Kamiya K, et al. Corneal biomechanical properties in normal-tension glaucoma. Acta Ophthalmol. 2011;90:e48-e53.

21. Mansouri K, Leite MT, Weinreb RN, et al. Association between corneal biomechanical properties and glaucoma severity. Am J Ophthalmol. 2012;153:419-427.

22. De Moraes CV, Hill V, Tello C, et al. Lower corneal hysteresis is associated with more rapid glaucomatous visual field progression. J Glaucoma. 2012;21:209-213.

23. Kaushik S, Pandav SS, Banger A, et al. Relationship between corneal biomechanical properties, central corneal thickness, and intraocular pressure across the spectrum of glaucoma. Am J Ophthalmol. 2012;153: 840-849.

24. Prata TS, Lima VC, Guedes LM, et al. Association between corneal biomechanical properties and optic nerve head morphology in newly diagnosed glaucoma patients. Clin Exp Ophthalmol. 2012;40:682-688.

25. Vu DM, Silva FQ, Haseltine SJ, et al. Relationship between corneal hysteresis and optic nerve parameters measured with spectral domain optical coherence tomography. Graefes Arch Clin Exp Ophthalmol. 2013; 251:1777-1783.

26. Asrani S, Zeimer R, Wilensky J, Gieser D, Vitale S, Lindenmuth K Large diurnal fluctuation in intraocular pressure are an independent risk factor in patients with glaucoma. J Glaucoma. 2000;9(2):134-142.
Clinical Ophthalmology

\section{Publish your work in this journal}

Clinical Ophthalmology is an international, peer-reviewed journa covering all subspecialties within ophthalmology. Key topics include: Optometry; Visual science; Pharmacology and drug therapy in eye diseases; Basic Sciences; Primary and Secondary eye care; Patien Safety and Quality of Care Improvements. This journal is indexed on

Submit your manuscript here: http://www.dovepress.com/clinical-ophthalmology-journal

\section{Dovepress}

PubMed Central and CAS, and is the official journal of The Society of Clinical Ophthalmology (SCO). The manuscript management system is completely online and includes a very quick and fair peer-review system, which is all easy to use. Visit http://www.dovepress.com/ testimonials.php to read real quotes from published authors. 